\title{
Implementing electronic health system in Nigeria: perspective assessment in a specialist hospital
}

\author{
Igbo Gabriel Alobo', Tolulope Soyannwo², Godwin Ukponwan³ ${ }^{3}$ Simon Akogu', \\ Abubakar Matthew Akpa ${ }^{4}$, Kazeem Ayankola
}

\section{Author details:}
a) Phones: +2348036570340; E-Mails: Gabriel.Alobo@jhpiego.org; Alobogab@gmail.com;
b) Phones: +2347038152631;Email: Tolulope.Soyannwo@SavetheChildreninternational.com;
c) Phones: +2348032375394; Email: pronosa@yahoo.co.uk;
d) Phone: +2348036005227; Emails: akoguspo@gmail.com;
e) Phone +2348036005227; matthewakpa@yahoo.com;
f) Phone +2347037727387; kazeem_ayankola@ng.jsi.com

1. Maternal Health Department Jhpiego an affiliate of Johns Hopkins University Nigeria field office.

2. Newborn Health Department Save the Children International Nigeria Field Office.

3. Department of Obstetrics and gynecology Kogi State Specialist Hospital, Lokoja.

4. Department of Obstetrics and gynecology Kogi State University.

5. Child Health Department John Snow International.

\begin{abstract}
Background: Perspectives on the pioneering work of Electronic Health Recording (EHR) system in Nigeria was studied Objectives: To determine health workers perception, challenges, motivation and satisfaction with EHR.

Methodology: This was a descriptive cross sectional study using structured questionnaire to assess health workers perspective on EHR system at Kogi State Specialist Hospital.

Results: A total of 35 consenting health workers with an mean age of $39.4( \pm 7.6)$ years using EHR were assessed. The mean daily work hour was $8.0( \pm 2.4$ hours) and median client load per participant was 20 daily. On perceptions, $74.3 \%$, $52.9 \%, 45.5 \%$ and $60.0 \%$ were comfortable, well-motivated, satisfied and competent with EHR. The advantages were reduction in transcription cost (88.5\%), Paper work (97.1\%), administrative cost $(91.4 \%)$, errors $(82.9 \%)$ and it captures, provides more services including timely access and ease research in $94.3 \%, 74.3 \%, 94.3 \%$ and $82.9 \%$ respectively. Challenges were threat to patient privacy, poor internet, information overload, power outages, incomplete and inaccurate information in $17.0 \%, 65.7 \%, 31.5 \%, 62.9 \%, 37.1 \%$ and $22.9 \%$ respectively.

Conclusion: Health workers were comfortable and satisfied with EHR and it eased their work.Scaling up EHR would reduce administrative cost, transcription errors and paper works to mitigate poor quality data from Nigeria a great contributor to global morbidities/mortalities
\end{abstract}

Keywords: Electronic health records; perception; Kogi state; Nigeria.

DOI: https://doi.org/10.4314/ahs.v20i2.50

Cite as: Alobo IG, Soyannwo T, Ukponwan G, Akogu S, Akpa AM, Ayankola K. Implementing electronic health system in Nigeria: perspective assessment in a specialist hospital. Afri Health Sci. 2020; 20(2): 948-954. https:/ / doi.org/10.4314/ abs.v20i2.50

\section{Corresponding author:}

Igbo Gabriel Alobo,

Maternal Health Department Jhpiego an affiliate

of Johns Hopkins University Nigeria field office

Phones: +2348036570340 ;

E-Mails: Gabriel.Alobo@jhpiego.org;

Alobogab@gmail.com

\section{Introduction}

One of the World Health Organizations six building blocks of effective health strengthening is the health information system. Data availability, quality and use are often a problem in Nigeria where the District Health Information Software 2 (DHIS2) is the major source. Challenges highlighted by some studies in Nigeria on data quality include poor data quality, incomplete data, 
inconsistencies in data reporting and untimely data submission. ${ }^{2,3,4}$ One of the factors propelling this problem is the reliance on manual method of inputting data. Concerning this, the need for a functional well led automated health data management has been advocated to strengthen the health system. ${ }^{5}$

Meeting this is often a challenge due to low manpower, infrastructures, inadequate financing mechanism, inadequate political will and poor knowledge of computers and information technology for health recording. In facilities where EHR was embraced, there was only partial deployment. ${ }^{6}$

Ross et al in a review of forty-four studies from North America and Europe identified barriers to implementation of EHR as adaptability, complexity, cost, external policy and incentives. Others were personal attributes such as knowledge, beliefs, computer skills, abilities and experience. Strategic planning, engagement of champions monitoring and evaluation were considered important success factors. ${ }^{7}$ Ajami et al in another systematic review of 32 studies found that the important factor limiting implementation was health workers resistance to change. ${ }^{8}$ Kanan et al found that collecting a pool of data electronically has an advantage over paperwork in the retrieval of data for the management of chronic disease conditions. ${ }^{9}$

Electronic Health Record (EHR) can be described as the use of health information technology (HIT), including patient health information and data, clinical decision support, results management and central data repositories, and order entry management technologies such as computerized physician order entry (CPOE), to support the organization and delivery of care. It assists with longitudinal collection of electronic health information about individual patients and population. ${ }^{10}$

It has been recognized as a system that has a wide range of benefits such as judicious use of physician time, improve patient safety, improve health outcomes and increase efficiency. It has produced multiple opportunities for health research, driven by huge data base including genome sequencing, and medical images that could be exchanged electronically. ${ }^{11}$ Although, EHR was not found to increase overall patient outcome and quality of care, when fully deployed, it was associated with a reduction of in-patient mortality, readmission and patient safety. ${ }^{12}$
Kogi State Specialist Hospital is one of the few health centers in Nigeria operating an integrated electronic health record system. The system operates such that ongoing consultations can be accessed by other sectors of the hospital real-time. This may just be the beginning of the electronic switch over in Nigeria healthcare. Kogi State Ministry of Health $(\mathrm{SMOH})$ which regulates health practice in the state has an objective of strengthening the Health Management Information System (HMIS). The incepton of the electronic medical recording system is aimed at realizing this objective. Each month, the ministry in collaboration with international partners spends huge amount for data collation, validation and reporting including support for the uploading into the DHIS2 which is mostly done manually. Despite the huge investments, the data reporting rate for the state remain a paltry $45 \%$ to $60 \%$. This data provides a basis for the state to seek assistance for a well developed electronic platform to help them achieve high data reporting rate. Built on solid evidence, the global direction is currently electronic health record and the return on investment appears high. As the current system of data management using papers is not working in the country, the need for innovation becomes imperative. Hence, this study aims to seek health workers perception of electronic health record to guide policies on scaling up.

\section{Methodology \\ Study site}

The study was conducted in Kogi State Specialist Hospital in Lokoja the capital city of Kogi State, North central Nigeria. The hospital runs 24 hour service with a client flow of over 300 daily. It was established in 2007. The deployment of CarePlus EMR at the center was successfully carried out with huge support from the staff and officers of the center and commenced electronic health recording in 2013. The features of the Electronic registration of patients include, National Health Insurance Scheme (NHIS) management, Cashless payment integration, Easy integration with Short Message Service (SMS) servers for messaging, Electronic Identification for patients, Bed assignment, Electronic prescription, Laboratory management for orders, reporting and consumables, Electronic X-RAY, Purchase Order, Easy and quick retrieval of patient records, Diagnosis based on World Health Organization (WHO) International Classification of Disease (ICD) 10 standard, Drug inventory control, Integrated reporting Intelligence System and HL7 Support via Mirth Connect which puts the hospital at HIMSS stage 5. 


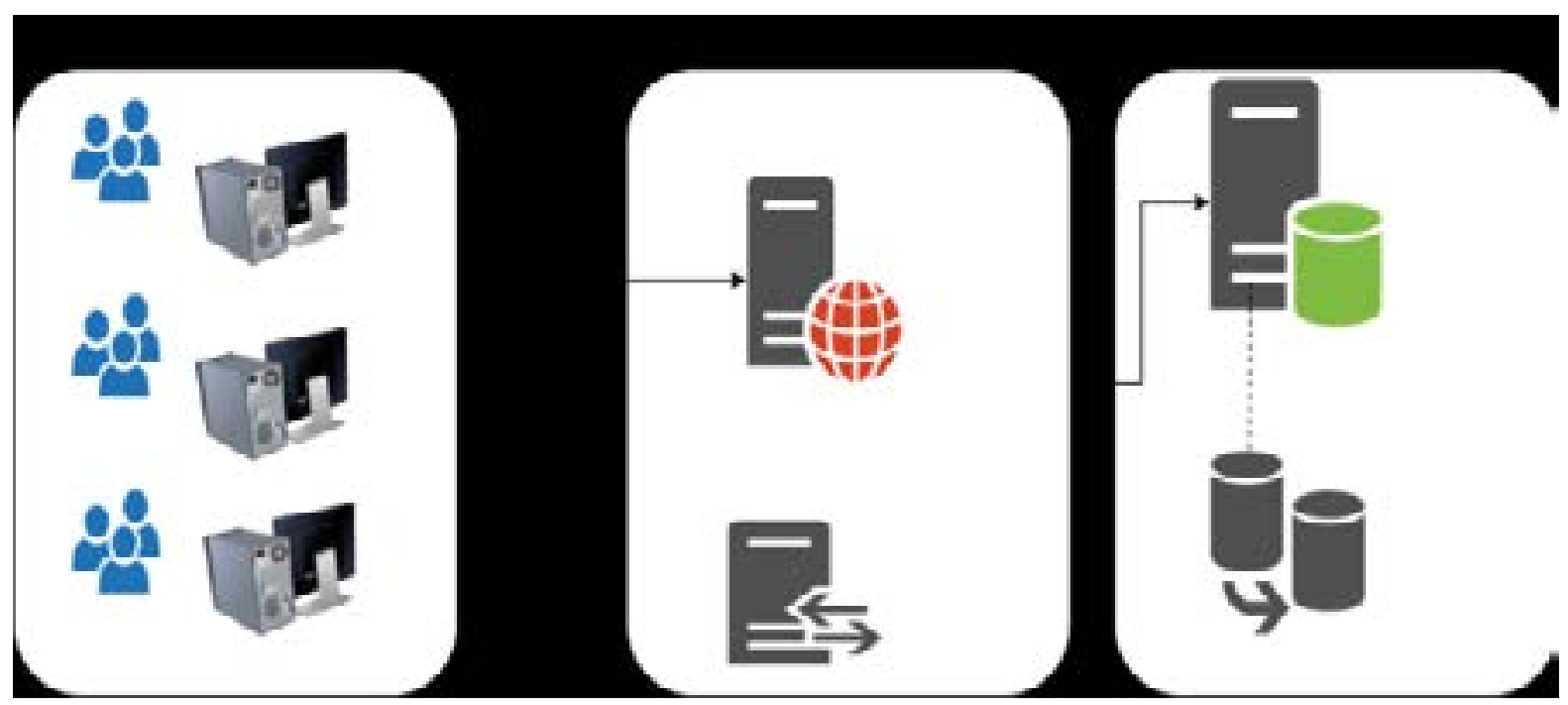

The hospital has specialized care in pediatrics, radiology, pathology, dentistry, surgery, internal medicine, obstetrics and gynecology amongst others.

\section{Study population}

Hospital management staffs, doctors, nurses, laboratory technologist, pharmacist and Health Management Information System (HMIS) officers were recruited for the study.

\section{Sampling technique}

Purposive sampling technique was employed to select the respondents. Consenting respondents were considered eligible for the study

\section{Study design}

This study was a descriptive cross sectional study.

\section{Sample size}

Thirty- five respondents trained on EHR consented and were sampled for the study

\section{Data collection methods}

Data was collected using a structured questionnaire. The instrument contained section 1 which assessed the socio-demographic characteristics. Section 2 assessed the perspective of health workers EHR. Likert scale was used in assessing health workers perspective on electronic health record. Likert scale comprises of not at all " 0 ", fair graded " 1 " and good graded " 2 ". Section 3 of the instrument assed the benefits of EHR while section 4 assessed the challenges of EHR. Ethical approval was sought from the Ethical committee of the hospital.

\section{Results}

A total of 35 health workers who were trained and are using EHR and gave consent were recruited into the study.

Most $19(56 \%)$ of the participants were in the age bracket 20-39years and mean age was 39.4 (7.6 \pm years). Majority of the respondents $25(71.4 \%)$ were Christians. A higher percentage of the respondents $10(31.4 \%)$ were Ebira by tribe and most of the respondents 12(34.3\%) interviewed were doctors. A larger percentage 30(85.7\%) of the respondents were married. The mean years post qualification was 11.7 ( \pm 5.0 years), mean years of working in the hospital was 7.1 ( \pm 3.5years), median years of working in the department was 6 years, mean daily working hours was $8.0( \pm 2.4$ hours) and median client load per person was 20 . 
See Table 1 below (socio-demographic characteristics)

\begin{tabular}{|l|r|}
\hline Variable( $\mathrm{N}=35)$ & Frequency (\%) \\
\hline Age $(\mathrm{yrs})(\mathrm{N}=34)$ & $19(56.0)$ \\
$20-39$ & $15(44.0)$ \\
$40-59$ & \\
\hline Marital status & $5(14.3)$ \\
Single & $30(85.7)$ \\
Married & \\
\hline Cadre & $12(34.3)$ \\
Doctors & $8(22.9)$ \\
Nurse & $1(2.9)$ \\
Physiotherapist & $2(5.7)$ \\
Pharmacist & $1(2.9)$ \\
Lab Scientist & $11(31.4)$ \\
Others* & \\
\hline Ethnic group & $8(22.9)$ \\
Yoruba & $10(28.6)$ \\
Igala & $11(31.4)$ \\
Ebira & $2(5.7)$ \\
Igbo & $4(11.4)$ \\
Others** & \\
\hline Religion & $25(71.4)$ \\
Christians & $10(28.6)$ \\
Muslims & \\
\hline$*$ (Accountan ICT oficers)** (Nupe Bassa)
\end{tabular}

*(Accountant, ICT officers) ** (Nupe, Bassa,)

Table 2 shows the perception towards EHR. Concern- were comfortable, well-motivated, satisfied and compeing it, $74.3 \%, 52.9 \%, 45.5 \%$ and $60.0 \%$ of respondents tent with EHR

Table 2: Perception of health workers on electronic health record (EHR)

\begin{tabular}{|l|l|l|l|}
\hline Variable(N= 35) & $\begin{array}{l}\text { Not at } \\
\text { all (\%) }\end{array}$ & Fair (\%) & Good (\%) \\
\hline $\begin{array}{l}\text { Comfortable with } \\
\text { computers }\end{array}$ & 0 & $9(25.7)$ & $26(74.3)$ \\
\hline $\begin{array}{l}\text { Experience with computers } \\
\mathrm{N}=34\end{array}$ & 0 & $14(41.2)$ & $20(58.8)$ \\
\hline $\begin{array}{l}\text { Motivation with computers } \\
\mathrm{N}=34\end{array}$ & $2(5.9)$ & $15(44.1)$ & $18(52.9)$ \\
\hline $\begin{array}{l}\text { Satisfaction with } \\
\text { computers } \\
\mathrm{N}=33\end{array}$ & $2(6.0)$ & $16(48.5)$ & $15(45.5)$ \\
\hline $\begin{array}{l}\text { Absence of coding } \\
\text { problems }\end{array}$ & $12(34.3)$ & $21(60.0)$ & $2(5.7)$ \\
\hline Competence with EHR & $2(5.7)$ & $12(34.3)$ & $21(60.0)$ \\
\hline
\end{tabular}

The advantages were reduction in transcription cost $(88.5 \%)$, reduced paper work $(97.1 \%)$, administrative cost $(91.4 \%)$, errors $(82.9 \%)$ and it captures, provides more services including timely access and ease research in $94.3 \%, 74.3 \%, 94.3 \%$ and $82.9 \%$ respectively. 
Table 3: Benefits of HER

\begin{tabular}{|l|l|l|l|}
\hline Variable (N=35) & Yes (\%) & No (\%) & $\begin{array}{l}\text { I don’t know } \\
(\%)\end{array}$ \\
\hline Transcription cost & $31(88.5)$ & $1(2.9)$ & $3(8.6)$ \\
\hline Paper & $34(97.1)$ & $1(2.9)$ & - \\
\hline Administration & $32(91.4)$ & $3(8.6)$ & - \\
\hline More service & $26(74.3)$ & $9(25.7)$ & - \\
\hline Capture all service & $33(94.3)$ & $2(5.7)$ & - \\
\hline Timely access & $33(94.3)$ & $2(5.7)$ & - \\
\hline Research & $29(82.9)$ & $4(11.4)$ & $2(5.7)$ \\
\hline Prone to errors & $29(82.9)$ & $4(11.4)$ & $2(5.7)$ \\
\hline $\begin{array}{l}\text { Increase } \\
\text { productivity }\end{array}$ & $29(82.9)$ & $4(11.4)$ & $2(5.7)$ \\
\hline
\end{tabular}

Challenges encountered were threat to patient privacy, poor internet, information overload, power outages, in- complete and inaccurate information in $17.0 \%, 65.7 \%$, $31.4 \%, 62.9 \%, 37.1 \%$ and $22.9 \%$ respectively.

Table 4: Challenges of HER

\begin{tabular}{|l|l|l|l|}
\hline Variable (N=35) & Yes (\%) & No (\%) & $\begin{array}{l}\text { I don't know } \\
\mathbf{( \% )}\end{array}$ \\
\hline Privacy breached & $6((17.1)$ & $29(82.9)$ & - \\
\hline Internet issues & $23(65.7)$ & $12(34.3)$ & - \\
\hline Work overload & $11(31.4)$ & $21(60.0)$ & $3(8.6)$ \\
\hline $\begin{array}{l}\text { Incomplete patient } \\
\text { information }\end{array}$ & $13(37.1)$ & $19(54.3)$ & $3(8.6)$ \\
\hline $\begin{array}{l}\text { Inaccurate patient } \\
\text { information }\end{array}$ & $8(22.9)$ & $26(74.3)$ & $1(2.8)$ \\
\hline Power outage & $22(62.9)$ & $11(31.4)$ & $2(5.7)$ \\
\hline
\end{tabular}

Data source: Kogi State Specialist Hospital, Lokoja, Kogi State

\section{Discussion}

Strengthening the health system requires actionable data. Availability of reliable and reproducible data is often a challenge in Nigeria where the use of data for decision making and clinical governance is at its infancy.While this is a challenge with many agencies, the ability to operate a hospital data electronically for 5 years shows that the prospect for this system is high.

The volume of health record is huge and it will continue to increase. Storing and retrieving this data is often a challenge. For the health system to keep up with the ever increasing health records and provide real time health care, some innovations may be required. The manpower need to manage paper work is huge and can be a challenge in emergency settings. The Health system in this study like others runs on roasters involving shifts, calls, and days only and night only activities. Lives can be endangered when the connection between the different units, segments and experiences of the managers of health system cannot be connected and automated. Searching for vital information such as laboratory results and previous reactions that can be automated is often a challenge. This hospital has met this challenge with the deployment of this system.

Many studies supported satisfaction of physician with EHR. In this study, there was good motivation and satisfaction with EHR with other advantages reported such as reduction in transcription cost, reduced paper work, reduced administrative cost, timely access to data and ease of research. Positive effect of EHR on research work as seen by Coorevits et al was also supported in this study as respondent gave a positive effect of EHR on ease of research. ${ }^{10,13}$

Challenges of EHR mentioned in this study include threat to patient privacy, poor internet, information 
overload, power outages, incomplete and inaccurate information. Findings from our study is in consonance with studies done by Ajami and Arab-Chadegani and Ross et al which also reported internet services and power outages as some of the problems encountered. These would require more investment and backups. ${ }^{7,8}$

On the other hand, EHR falls short of being accepted by all cadres of the medical profession as many of them are presented as a template. One of this is the charting of patients information by nurses and the inability to describe peculiar clinical findings on readymade templates. ${ }^{14}$ Patient also finds physician's attention and engrossment with computers and electronics during consultations distracting. They were more satisfied when there was eye contact. ${ }^{15}$

\section{Conclusions and recommendations}

Deployment and use of EHR system is the first step on the journey to providing an enhanced health care systems and it has shown to make health systems more efficient and more responsive to providers, patients and health administrators' needs. This study demonstrated satisfaction with EHR amidst challenges encountered with EHR. Considerations must be given to scaling up EHR to all health facilities in the state and the country at large. Investment in resolving power outages and poor internet connectivity should also be considered.

\section{Conflict of interest}

There was no conflict of interest

\section{Funding}

There was no external funding. All expenses were borne by the authors

\section{References}

1. Ohiri K, Ukoha NK, Nwangwu CW, Chima CC, Ogundeji YK, Rone A \& Reich MR. An Assessment of Data Availability, Quality, and Use in Malaria Program Decision Making in Nigeria, Health Systems \& Reform, 2016;2:4, 319-330. PubMed

2. Omoleke SA, Tadesse MG. A pilot study of routine immunization, data quality in Bunza Local Government area: causes and possible remedies. The Pan African Medical Journal. 2017; 27:239.

3. Abubakar AA, Sambo MN, Idris SH, Sabitu K, Nguku P. Assessment of integrated disease surveillance and response strategy implementation in selected Local Government Areas of Kaduna state. Ann Nigerian Med serial online 2013; 7:14-9. PubMed
4. Akanbi MO, Ocheke AN, Agaba PA, Daniyam CA, Agaba EI, Okeke EN, Ukoli CO. Use of Electronic Health Records in sub-Saharan Africa: Progress and challenges. J Med Trop. 2012; 14(1): 1-6. PubMed

5. Welcome MO. The Nigerian health care system: Need for integrating adequate medical intelligence and surveillance systems. J Pharm Bioallied Sci. 2011 OctDec; 3(4): 470-478.

6. Okuboyejo SO. An Investigation of the Factors Influencing the Adoption of E-Health Services: The Case for Selected Hospitals in Lagos State, Nigeria. Afr $J$ Comp \& ICTs Special Issue on ICTs in the African Environment 2012; (5) 4:2

7. Ross J, Stevenson F, Lau R, Murray E. Factors that influence the implementation of e- health: a systematic review of systematic reviews (an update). Implementation Science: IS. 2016; 11:146.

8. Ajami S, Arab-Chadegani R. Barriers to implement Electronic Health Records (EHRs). Materia Socio-Medica. 2013; (25)3:213-215.

9. Kannan V, Fish JS, Mutz JM, Carrington AR, Lai K, Davis LS, Youngblood JE, Rauschuber MR, Flores KA, Sara EJ, Bhat DG, Willett DL. Rapid Development of Specialty Population Registries and Quality Measures from Electronic Health Record Data. An Agile Framework. Methods Inf Med. 2017; 56(99):e74-e83.

10. Orchard MC, Dobrow MJ, Paszat L, Jiang H and Brown P. Access to electronic health records by care setting and provider type: perceptions of cancer care providers in Ontario, Canada. BMC Medical Informatics and Decision Making 2009, 9:38.

11. Coorevits P, Sundgren M, Klein GO, Bahr A, Claerhout B, Daniel C, Dugas M, Dupont D, Schmidt A, Singleton P, De Moor G, Kalra D. Ghent University, Ghent; The EuropeanInstitute for Health Records (EuroRec), Sint-Martens-Latem, Belgium; AstraZeneca R\&D, Mölndal, Sweden; University of Science and Technology, Trondheim, Norway; Sanofi R\&D, Chilly- Mazarin, Paris, France; Institute of Medical Informatics, University of Münster, Münster, Germany; Data Mining International SA, Geneva; F Hoffmann-La Roche Ltd, Basel, Switzerland; Cambridge Health Informatics, Cambridge; University College London, London, UK. Electronic health records: new opportunities for clinical research. J Intern Med 2013; 274: 547-560. PubMed 12. Yanamadala, S, Morrison D, Curtin C, McDonald K, Hernandez-Boussard T. Electronic Health Records and Quality of Care: An Observational Study Modeling Impact on Mortality, Readmissions, and Complications. Medicine: May 2016;(95)19: e3332. PubMed 
13. Holanda AA, do Carmo E Sá HL, Vieira AP, Catrib AM. Use and satisfaction with electronic health record by primary care physicians in a health district in Brazil. J Med Syst. 2012 Oct;36 (5):3141-9.
14. Frazier K. Electronic Health Records. AJN, American Jounal of Nursing: 2017; 117 (6):10.

15. Farber NJ, Liu L, Chen Y. EHR use and patient satisfaction: What we learned. J Fam Pract. 2015; 64(11):68789,693-696 